Ambiente \& Água - An Interdisciplinary Journal of Applied Science
ISSN 1980-993X - doi:10.4136/1980-993X
www.ambi-agua.net
E-mail: ambi-agua@agro.unitau.br

\title{
Avaliação da toxicidade dos extratos do Araribá (Centrolobium tomentosum) com utilização do bioensaio com Artemia salina
}

\author{
doi: 10.4136/ambi-agua.1374
}

Received: 16 Aug. 2013; Accepted: 18 Nov. 2013

\author{
Roberto Carlos de Sá Silva ${ }^{1 *}$; Júlio César Raposo de Almeida ${ }^{1}$; Ana Aparecida da Silva \\ Almeida $^{1}$; Gokithi Akisue ${ }^{2}$; Matheus Diniz Gonçalves Coelho ${ }^{2}$; José Roberto Pereira ${ }^{3}$

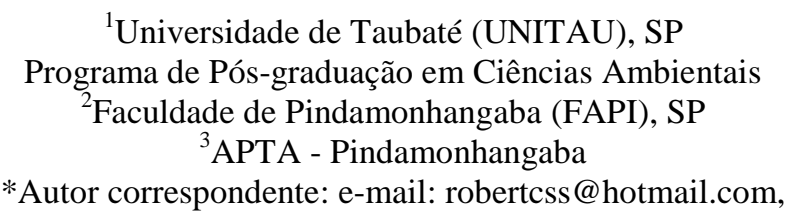 \\ jcraposo@uol.com.br, anasilva@unitau.br, eakisue@ajato.com.br, matheusdgc@yahoo.com.br, \\ jroberto@apta.sp.gov.br
}

\section{RESUMO}

Desde os primórdios da medicina o homem tem utilizado produtos naturais para o tratamento de doenças. Atualmente tem havido maior interesse no estudo com plantas de uso popular, em várias partes do mundo, visando a suas características terapêuticas. Nesse contexto, a espécie Centrolobium tomentosum, Fabaceae, conhecida popularmente como Araribá ou Araruva, tem sido empregada na medicina popular brasileira como adstringente, para o tratamento de feridas e contusões, devido à grande quantidade de taninos presentes na casca. Este trabalho teve como objetivo principal realizar ensaios de toxicidade para avaliar a atividade biológica dos extratos etanólicos de $C$. tomentosum e, como objetivos específicos, obter extratos concentrados de folhas, casca e lenho dessa espécie, além de determinar os teores de fenóis e taninos totais dos extratos obtidos. Amostras dos constituintes do araribá foram coletadas para obtenção de extratos etanólicos pelo processo de percolação. Em seguida foi realizada a identificação química qualitativa dos taninos hidrolisáveis e dos taninos condensados. Foi utilizado o método de Folin-Ciocalteu na quantificação do teor de fenóis e o método de precipitação com caseína na determinação dos taninos totais. Os extratos foram submetidos à avaliação de toxicidade com a utilização do bioensaio com Artemia salina e, o extrato etanólico da casca de $C$. tomentosum apresentou moderada toxicidade, com valor estimado de $\mathrm{CL}_{50}=416 \mu \mathrm{g} \cdot \mathrm{ml}^{-1}$, enquanto os extratos de folhas e lenho dessa espécie apresentaram baixa toxicidade, com $\mathrm{CL}_{50}=537 \mu \mathrm{g} \cdot \mathrm{ml}^{-1}$ e $826 \mu \mathrm{g} \cdot \mathrm{ml}^{-1}$, respectivamente.

Palavras-chave: medicamentos, fitoterápicos, taninos, camarão de salina.

\section{Evaluation of the toxicity of Araribá (Centrolobium tomentosum) using brine Shrimp test}

\section{ABSTRACT}

Since the dawn of medicine, man has used natural products for the treatment of disease. There has been a recent increase in studies of the therapeutic characteristics plants in popular use in many places of the world. In this context, the species Centrolobium tomentosum, 
Fabaceae, known popularly as Araribá or Araruva, is used in Brazilian folk medicine as an astringent for wound treatment and bruises due to the large amount of tannins contained in the bark. This work used toxicity tests to assess the biological activity of ethanolic extracts from C. tomentosum with the specific objectives of obtaining concentrated extracts from the bark and wood of this species and determining the total phenols and tannins present in these extracts. We collected araribá samples in order to obtain ethanolic extracts through the percolation process. We then made a qualitative chemical identification of hydrolysable tannins and condensed tannins. We used the Folin-Ciocalteu method for the phenols quantification and the casein precipitation method for the tannins determination. The toxicity of extracts was evaluated using the brine shrimp bioassay (Artemia salina), in which the $C$. tomentosum bark extract showed moderate toxicity, with estimated LC50 $=416 \mu \mathrm{g} \cdot \mathrm{ml}^{-1}$, whereas the leaves and wood extracts of this species showed low toxicity with LC50 = 537 $\mu \mathrm{g} . \mathrm{ml}^{-1}$ and $826 \mu \mathrm{g} \cdot \mathrm{ml}^{-1}$, respectively.

Keywords: phytotherapeutic, drugs, tannins, brine shrimp.

\section{INTRODUÇÃO}

O homem tem utilizado produtos naturais para tratamento de doenças desde os primórdios da medicina. Os indígenas, curandeiros e líderes religiosos, obtiveram conhecimento sobre as plantas medicinais, que era a única opção terapêutica em diversas comunidades e grupos étnicos (Elisabetsky e Souza, 2003; Lopez, 2006; Chew et al., 2012; Dalarmi, 2012).

Nas últimas décadas, em várias partes do mundo, tem havido um maior interesse no estudo de plantas de uso popular, pelo seu valor terapêutico. As propriedades medicinais das plantas têm sido pesquisadas devido ao seu potencial farmacológico, baixa toxicidade e viabilidade econômica (Prashant et al., 2008).

A fitoterapia, recurso terapêutico caracterizado pelo uso de plantas medicinais em diferentes apresentações farmacêuticas, apresenta adesão de grande parte da população mundial. Diversos estudos relatam a importância da divulgação dessa terapêutica complementar para a saúde pública, destacando a importância dos países em desenvolvimento, com sua rica biodiversidade (Brasil, 2006; Mossi et al., 2009).

Empregada na medicina popular brasileira, a espécie Centrolobium tomentosum Guilhemin ex Benth., Fabaceae, conhecida popularmente como araribá ou araruva, nativa do Brasil e pertencente ao bioma da mata atlântica, é utilizada como adstringente, no tratamento de feridas e contusões, devido à grande quantidade de taninos presentes em seus constituintes (Correa, 1926; Diaz, 1992).

Essa espécie apresenta $28 \%$ a $43 \%$ de tanino na casca e entre 142 plantas tanantes conhecidas no mundo, apresentou uma das maiores concentrações de tanino na casca, superada apenas pelo quebracho (Schinopsis balansae Engl.) (Bastos, 1952 apud Carvalho, 2005).

Os taninos, macromoléculas presentes em várias espécies vegetais, são classificados como hidrolisáveis ou condensados de acordo com sua estrutura química. Os taninos hidrolisáveis são constituídos por monômeros de ácido gálico ou elágico, enquanto os taninos condensados são formados por meio de polimerização de unidades catequínicas. Os compostos tânicos são produtos com amplo uso na indústria de curtimento de couro, além de outras aplicações industriais e farmacológicas. Os taninos condensados também podem ser utilizados na produção de adesivos destinados à colagem de diferentes produtos de madeira, com destaque para os taninos da casca da acácia negra, que são os mais utilizados para essa finalidade (Gonçalves et al., 2010; Paiva et al., 2002; Tostes et al., 2005). 
Os taninos ocorrem naturalmente em plantas e devido à presença de estruturas aromáticas em sua molécula são denominados polifenóis. Substâncias tanantes são comuns em frutas, em chás, chocolate, em gramíneas, como sorgo e milho, em arbustos e árvores leguminosas, como na Acacia spp e Centrolobium tomentosum. Os compostos tânicos estão localizados principalmente no interior de vacúolos ou próximos da superfície absorvente, entretanto, nesses locais eles não interferem no metabolismo da planta. Somente após rompimento das células eles passam a atuar no metabolismo vegetal. $\mathrm{O}$ metabolismo microbiano e a digestão gástrica transformam esses taninos em metabólitos de peso molecular baixo. Alguns desses metabólitos apresentam toxicidade e estão associados a hemorragias gastrointestinais e necrose hepática ou renal, principalmente em monogástricos (Cannas, 2001; Monteiro et al., 2005; Fonseca e Librandi, 2008).

Os prováveis efeitos tóxicos que as plantas podem apresentar, quando usadas inadequadamente, ainda são desconhecidos ou, muitas vezes, ignorados, apesar da eficácia terapêutica apresentada por muitas espécies. Portanto, a investigação do potencial tóxico de plantas medicinais pode esclarecer importantes aspectos farmacológicos de seus constituintes, propiciando uma utilização segura, se respeitados seus possíveis riscos toxicológicos (Amaral e Silva, 2008).

Considerando a eventual toxicidade de produtos naturais, ensaios podem ser realizados para avaliação da segurança no tratamento com fitoterápicos. A necessidade de realizar ensaios com técnicas simples e rápidas levou à busca por novos testes. A letalidade de organismos simples tem sido utilizada para um monitoramento rápido e relativamente simples da resposta biológica onde exista apenas um parâmetro envolvido: morte ou vida. Portanto os resultados podem ser tratados estatisticamente com maior facilidade. $\mathrm{O}$ ensaio de letalidade permite a avaliação da toxicidade geral, sendo considerado essencial como bioensaio preliminar no estudo de compostos com potencial atividade biológica (Rodriguez et al., 2009).

Dentre os animais utilizados neste bioensaio destaca-se Artemia salina Leach, uma espécie de microcrustáceo marinho. Este ensaio determina a concentração letal média para $50 \%$ dos indivíduos $\left(\mathrm{CL}_{50}\right)$ em $\mu \mathrm{g} \cdot \mathrm{ml}^{-1}$ de compostos ou extratos de plantas, como observado em várias substâncias ativas conhecidas que apresentaram toxicidade neste ensaio (Cavalcante, 2000; Subhan et al., 2008; Rehman et al., 2009).

Os cistos de Artemia salina, além de permanecerem viáveis por longos períodos no estado seco, são encontrados facilmente no comércio a baixo custo. Essas características contribuíram para a popularização deste teste, sobretudo a partir da década de 90 (Meyer et al., 1982; Igarashi, 2008).

O objetivo principal deste trabalho foi realizar testes toxicológicos com extratos concentrados de araribá frente à Artemia salina e determinar os fenóis e taninos totais dos extratos das folhas, casca e lenho do araribá.

\section{MATERIAL E MÉTODOS}

\subsection{Coleta de material vegetal}

Amostras de cascas, folhas e lenho da espécie arbórea Centrolobium tomentosum, popularmente conhecido como araribá, foram coletadas no mês de maio de 2012. Os componentes vegetais (folhas, cascas e lenho) foram colhidos de plantas adultas de araribá encontradas no campus do Departamento de Ciências Agrárias da Universidade de Taubaté, situado entre as coordenadas $23^{\circ} 00^{\prime} \mathrm{S}$ e $41^{\circ} 35^{\prime} \mathrm{W}$, na cidade de Taubaté, no Estado de São Paulo, Brasil.

A identificação do material coletado seguiu os padrões de taxonomia clássica, feita com base em caracteres morfológicos florais (Erbano, 2010). 


\subsection{Obtenção dos extratos concentrados}

As amostras coletadas foram secas em estufa com circulação forçada de ar a $50^{\circ} \mathrm{C}$ por 48 horas, no Laboratório de Solos da UNITAU. Depois as amostras foram enviadas ao Laboratório de Farmacognosia onde foram picadas, trituradas e em seguida pulverizadas em moinho. Após pesagem obtiveram-se $718 \mathrm{~g}$ das folhas, $541 \mathrm{~g}$ das cascas e $771 \mathrm{~g}$ do lenho. $\mathrm{O}$ método de extração foi a percolação, utilizando etanol a $70 \% \mathrm{v} / \mathrm{v}$ como líquido extrator (Farmacopéia Brasileira, 1959).

O processo foi conduzido até o momento em que o líquido percolado não apresentou coloração e o teste qualitativo para taninos hidrolisáveis e taninos condensados passaram a apresentar resultados negativos. Utilizou-se como metodologia para identificação química de taninos gálicos (hidrolisáveis) a reação com solução aquosa de acetato de chumbo e ácido acético glacial. Para pesquisa de taninos condensados (catequínicos) foi empregado o reativo de Wasicki (Akisue, 2002).

Os extratos fluidos foram colocados no roto-vapor para concentração. Em seguida os extratos concentrados foram colocados em estufa a $60^{\circ} \mathrm{C}$ até apresentarem peso constante. Foram obtidos $233 \mathrm{~g}$ do extrato concentrado das folhas, $55 \mathrm{~g}$ do extrato da casca e $57 \mathrm{~g}$ do extrato do lenho.

\subsection{Determinação de extrativos}

Foi utilizado o método de Folin-Ciocalteu para a determinação do teor e a atividade biológica dos taninos. O método baseia-se na reação de oxirredução entre compostos fenólicos e íons metálicos, produzindo pigmentos de cor azul. É indicado somente para a quantificação de fenóis totais, porque não diferencia os taninos dos outros fenóis. Contudo, a quantificação dos taninos totais é possível graças à propriedade que eles possuem de se ligarem às proteínas formando complexos, da maneira como ocorre no método da caseína (Folin e Ciocalteu, 1927; Monteiro et al., 2005; Kuskoski et al., 2006; Simões et al., 2010).

A curva padrão para fenóis e taninos foi realizada empregando-se uma solução aquosa padrão de ácido tânico a $0,1 \mathrm{mg} \cdot \mathrm{dL}^{-1}$.

\subsection{Determinação dos fenóis totais}

Os extratos concentrados foram diluídos a $0,5 \mathrm{~g} \cdot \mathrm{dl}^{-1}$ com etanol a $95 \%$ PA. Foi utilizado o método de Folin-Ciocalteu para a quantificação dos fenóis totais e o método da precipitação da caseína para a determinação dos taninos totais.

O teor de fenóis totais foi calculado em equivalente de ácido tânico, de acordo com a curva de calibração, considerando-se a média das leituras, e o resultado foi expresso em mg. $\mathrm{g}^{-1}$ de extrato concentrado.

\subsection{Determinação dos taninos totais}

Utilizou-se como metodologia a precipitação pela caseína, modificada, para a determinação dos taninos totais. $\mathrm{O}$ teor de taninos totais correspondeu à diferença entre $\mathrm{o}$ valor encontrado nessa dosagem e o obtido na determinação dos fenóis totais.

\subsection{Teste de toxicidade com Artemia salina}

O ensaio com o microcrustáceo Artemia salina é sugerido como um método simples que pode ser aplicado na pesquisa de fitoterápicos devido à boa correlação com testes in vivo (Meyer et al., 1982; Mayorga et al., 2010).

Os cistos de A. salina $(15 \mathrm{mg})$ foram eclodidos entre $23-28^{\circ} \mathrm{C}$ em salina artificial $(23 \mathrm{~g}$ de sal marinho e $0,7 \mathrm{~g} . \mathrm{l}^{-1}$ de bicarbonato de sódio em água destilada, acertando o $\mathrm{pH}$ entre $8 \mathrm{e}$ 9), com iluminação artificial e aeração constantes por 48 horas. Após esse período foi desligado o compressor por 10 minutos para que os cistos viáveis fossem para o fundo do 
aquário e as cascas subissem à superfície. Devido ao fototropismo positivo, os naúplios foram atraídos por uma pequena fonte de luz artificial colocada no meio do aquário, na parte externa, em ambiente com pouca iluminação e aspirados por uma pipeta de Pasteur, em quantidade necessária para o experimento (Figura 1).

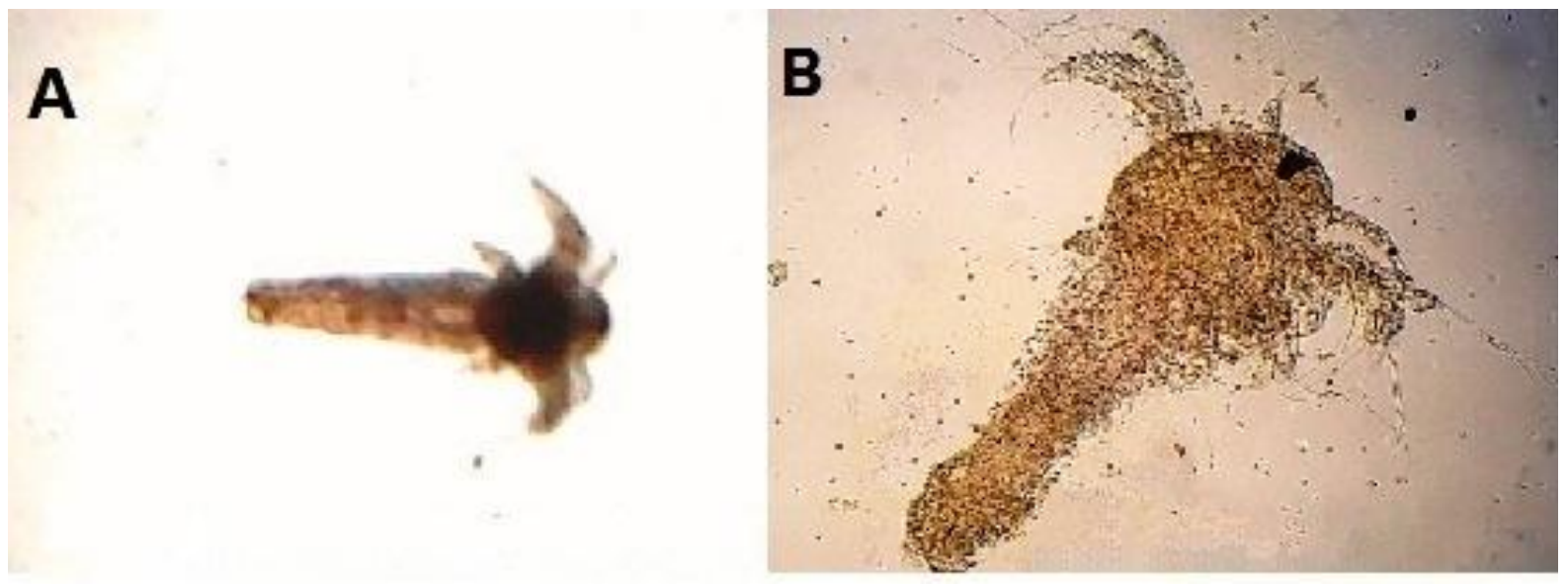

Figura 1. Náuplios de Artemia salina, (A) aumento de 40X; (B) aumento de 100X.

Os extratos etanólicos de araribá foram diluídos em salina artificial nas concentrações: 500, 1000, 1500, 2500, 5000 e $7500 \mu \mathrm{g} \cdot \mathrm{ml}^{-1}$. Como controle positivo foi utilizado o dicromato de potássio $0,55 \mathrm{~N}$ diluído em salina na concentração de $500 \mu \mathrm{g} \cdot \mathrm{ml}^{-1}$. Como controle negativo foi utilizado etanol $70 \%$ diluído em salina na concentração $1000 \mu \mathrm{g} \cdot \mathrm{ml}^{-1}$. Foram transferidos 10 náuplios de Artemia salina para essas soluções. O delineamento experimental foi feito ao acaso com 8 tratamentos (6 concentrações, 1 controle negativo, 1 controle positivo) e com 3 repetições. A contagem de náuplios mortos foi efetuada após $24 \mathrm{~h}$. A curva de sobrevivência foi traçada e após regressão exponencial foi estimada a Concentração Letal para $50 \%$ dos indivíduos $\left(\mathrm{CL}_{50}\right)$.

Dentre os animais utilizados neste bioensaio destaca-se Artemia salina Leach, uma espécie de microcrustáceo marinho. Este ensaio determina a concentração letal média para $50 \%$ dos indivíduos $\left(\mathrm{CL}_{50}\right) \mathrm{em} \mu \mathrm{g} \cdot \mathrm{ml}^{-1}$ de compostos ou extratos de plantas, como observado em várias substâncias ativas conhecidas que apresentam toxicidade (Cavalcante et al., 2000; Subhan et al., 2008).

\section{RESULTADOS E DISCUSSÃO}

\subsection{Estimativa dos taninos e fenóis totais}

Os teores de fenóis totais variaram de 3,4 a $8,2 \mathrm{mg} \cdot \mathrm{g}^{-1}$ e os taninos totais variaram de 1,6 a 4,4 mg. $\mathrm{g}^{-1}$, sendo a folha o constituinte com os valores mais altos (Tabela 1). Os teores encontrados foram inferiores aos detectados em vegetal do mesmo gênero (Pinzon-Torres et al., 2009).

Tabela 1. Rendimento dos extratos com análise do teor de fenóis e taninos totais obtidos dos constituintes da Centrolobium tomentosum.

\begin{tabular}{lccc}
\hline & Folha & Casca & Lenho \\
\hline Extrato concentrado $\left(\mathrm{g} \cdot \mathrm{kg}^{-1}\right.$ da amostra seca) & 324,5 & 101,7 & 73,9 \\
Fenois totais (mg.g $\mathrm{g}^{-1}$ do extrato concentrado) & 8,2 & 5,5 & 3,4 \\
Taninos totais (mg.g $\mathrm{g}^{-1}$ do extrato concentrado) & 4,4 & 3,1 & 1,6 \\
Fenois totais $\left(\mathrm{g} . \mathrm{kg}^{-1}\right.$ de amostra seca) & 5,9 & 3,0 & 2,6 \\
Taninos totais $\mathrm{g} \cdot \mathrm{kg}^{-1}$ de amostra seca) & 3,2 & 1,7 & 1,3 \\
\hline
\end{tabular}


Foi obtido um melhor rendimento do extrato concentrado das folhas do araribá e também um maior teor de fenóis e taninos totais, em comparação com os valores obtidos da casca e do lenho, diferente de resultados observados por outros pesquisadores, em cujos estudos o teor de taninos determinados na casca foi maior (Bastos, 1952 apud Carvalho, 2005).

A diferença nos teores de substâncias tanantes entre os experimentos deve-se, provavelmente, ao fato de que o rendimento de tanino depende da interação de diversos fatores como características genéticas, climáticas, pedológicas, manejo utilizado nos povoamentos e técnicas silviculturais. $\mathrm{O}$ crescimento, a qualidade e quantidade dos produtos obtidos são determinados pela interação entre esses fatores (Martinez, 2006).

\subsection{Toxicidade dos extratos de araribá sobre Artemia salina}

Foram estimados os valores da Concentração Letal 50\% $\left(\mathrm{CL}_{50}\right)$ para os extratos etanólicos do araribá, por meio do teste de toxicidade com Artemia salina (Figura 2), utilizando-se o programa estatístico BioEstat 5.0 (Ayres et al., 2007).

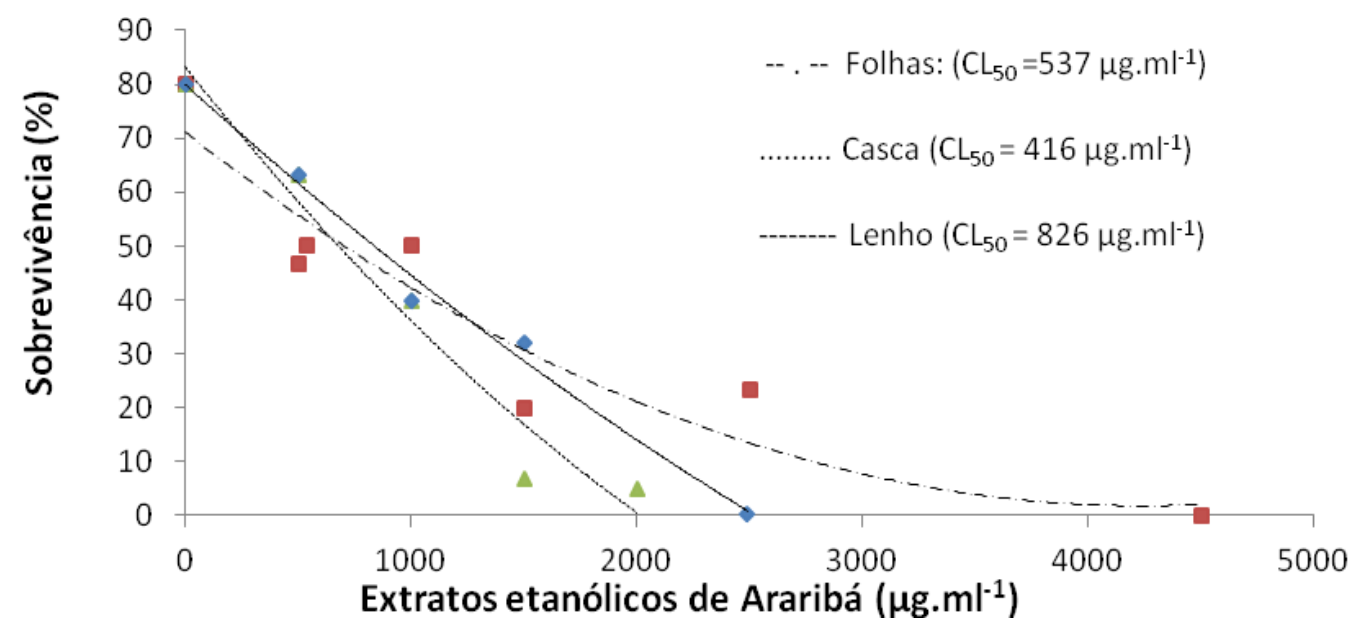

Figura 2. Percentual de náuplios sobreviventes de Artemia salina expostos à concentrações crescentes de extratos etanólicos do araribá (folhas, casca e lenho).

Após a regressão dos resultados do ensaio de toxicidade dos extratos do araribá sobre Artemia salina, utililizando-se a análise de variância e, a posteriori, o teste de Tukey ao nível de significância de $1 \%$, pôde-se concluir que o aumento da concentração dos extratos do araribá (casca, folhas e lenho) diminuiu a taxa de sobrevivência dos náuplios. Portanto, a análise dos resultados indicou toxicidade moderada do extrato etanólico da casca e toxicidade baixa dos extratos das folhas e do lenho do araribá, considerando forte toxicidade para valores de $\mathrm{CL}_{50}$ até $100 \mu \mathrm{g} \cdot \mathrm{ml}^{-1}$, moderada toxicidade para $\mathrm{CL}_{50}$ entre 100 e $500 \mu \mathrm{g} \cdot \mathrm{ml}^{-1}$, baixa toxicidade para $\mathrm{CL}_{50}$ entre $500 \mu \mathrm{g} \cdot \mathrm{ml}^{-1}$ e $1000 \mu \mathrm{g} \cdot \mathrm{ml}^{-1}$, e não tóxico acima de $1000 \mu \mathrm{g} \cdot \mathrm{ml}^{-1}$ (Nguta et al., 2011).

Estudos têm sido conduzidos com extratos de plantas ricas em substâncias aromáticas, como taninos e flavonoides, para avaliação da toxicidade por meio do ensaio com A. salina. No trabalho em que foram testados extratos de Anadenanthera falcata, Kilmeyera coreacea, Myracrodruon urundeuva e Pyrostegia venusta, por meio do ensaio com A. salina, os pesquisadores observaram, como efeito significante, a toxicidade dos extratos de Pyrostegia venusta e Anadenanthera falcata, e não toxicidade dos extratos de Kilmeyera coreacea e Myracrodruon urundeuva (Amaral e Silva, 2008).

Outro estudo com extrato etanólico obtido das folhas de Arruda (Montrichardia linifera) resultou em baixa toxicidade para Artemia salina (Costa et al., 2009).

Vários extratos do cipó-cravo (Tynnanthus fasciculatus MIERS) também passaram por ensaios fitoquímicos e toxicológicos, com utilização de A. salina como bioindicador. A 
prospecção fitoquímica indicou a presença de taninos, flavonoides e heterosídeos cardiotônicos para o extrato aquoso, etanólico e em diclorometano. $\mathrm{O}$ extrato aquoso do cipócravo apresentou $\mathrm{DL}_{50}=43,4 \mathrm{mgl}^{-1}$, o que indica alta toxicidade em comparação com dados da literatura (Carvalho et al., 2009).

\section{CONCLUSÃO}

Até onde se conhece, este é o primeiro trabalho que realizou a extração e quantificação das substâncias tanantes do araribá e, a posteriori, conduziu ensaios de toxicidade dos extratos obtidos frente ao microcrustáceo Artemia salina.

A espécie Centrolobium tomentosum, Fabaceae, tem potencial para a extração de taninos, apresentando, neste estudo, maior rendimento de compostos tânicos obtidos das folhas em comparação com os compostos obtidos da casca e do lenho.

Os extratos etanólicos do araribá apresentaram atividade biológica frente à A. salina, o que ficou demonstrado nos ensaios toxicológicos, nos quais o extrato da casca apresentou moderada toxicidade, enquanto os extratos das folhas e do lenho apresentaram baixa toxicidade.

A moderada toxicidade do extrato da casca do araribá tem potencial a ser explorado em pesquisas futuras, quando o efeito citotóxico se fizer necessário, como nos estudos sobre o tratamento de neoplasias. De outro modo, a baixa toxicidade dos extratos do lenho e das folhas do araribá poderá ser útil nas pesquisas com substâncias tanantes e adstringentes, após purificação de compostos e determinação de outras atividades biológicas e farmacológicas.

\section{AGRADECIMENTOS}

Os autores agradecem:

À Universidade de Taubaté (UNITAU) e à Universidade de Pindamonhangaba (FAPI) que disponibilizaram seus laboratórios.

Ao Prof. Dr. João Luiz Gadioli e seus Colaboradores, Maurício, Erlandsen e Jorge, do Laboratório de Solos da UNITAU.

Às estagiárias da FAPI, Mariana, Fábia e Fabiana, que colaboraram com dedicação.

\section{REFERÊNCIAS}

AKISUE, G. Farmacognosia: curso de identificação de drogas vegetais. São Paulo: Pharmakon, 2002.

AMARAL, E. A.; SILVA, R. M. G. Avaliação da toxidade aguda de angico (Anadenanthera falcata), Pau-Santo (Kilmeyera coreacea), Aroeira (Myracrodruon urundeuva) e CipóDe-São-João (Pyrostegia venusta), por meio do bioensaio com Artemia salina. Perquirēre, Patos de Minas, v. 5, n. 5., p. 16, 2008.

AYRES, M.; AYRES JR., M.; AYRES, D. L.; SANTOS, A. A. S. BioEstat 5.0: aplicações estatísticas nas áreas das ciências biomédicas. Belém: Sociedade Civil Mamirauá; Imprensa Oficial do Estado do Pará, 2007. 323 p.

BRASIL. Portaria n. 971, de 03 de maio de 2006. Dispõe e aprova a Política Nacional de Práticas Integrativas e Complementares (PNPIC) no Sistema Único de Saúde. Disponível em: http://bvsms.saude.gov.br/bvs/saudelegis/gm/2006/prt0971_03_05_2006.html. Acesso em: 18 jul. 2013. 
CANNAS, A. Tannins: fascinating but sometimes dangerous molecules. 17 Sep. 2001. Cornell University. Disponível em; <http://www.ansci.cornell.edu/plants/toxicagents/tannin.html>. Acesso em: 2 fev. 2014.

CARVAlho, C. A.; MATTA, S. L. P.; MElO, F. C. S. A.; ANDRADE D. C. F.; CARVALHO L. M.; NASCIMENTO P. C. et al. Cipó-Cravo (Tynanthus fasciculatus miers - Bignoniaceae): estudo fitoquímico e toxicológico envolvendo Artemia salina. Revista eletrônica de Farmácia, Bagé, v. 6, n. 1, p. 51-57, 2009.

CARVALHO, P. E. R. Araruva. Colombo: Embrapa florestas, 2005. 11 p.

CAVAlCANTE, M. F.; OLIVEIRA, M. C. C.; VELANDIA, J. R.; ECHEVARRIA, A. Síntese de 1,3,5-triazinas substituídas e avaliação da toxicidade frente à Artemia salina leach. Química Nova, Seropédica, v. 23, n. 1, p. 20-22, 2000. http://dx.doi.org/10.1590/S0100-40422000000100005

CHEW, A. L.; JESSICA, J. J. A.; SASIDHARAN, S. Antioxidant and antibacterial activity of different parts of Leucas aspera. Asian Pacific Journal of Tropical Biomedicine, v. 2, n. 3, p. 176-180, 2012. http://dx.doi.org/10.1016\%2FS2221-1691(12)60037-9

CORREA, M. P. Dicionário das plantas úteis do Brasil e das exóticas cultivadas. Serviço de Informação Agrícola, v. 6, n. 1, p. 777, 1926.

COSTA, E. S. S.; DOLABELA, M. F.; PÓVOA, M. M.; OLIVEIRA, D. J.; MÜLLER A. H. Revista brasileira de Farmacognosia, v. 19, n. 4, p. 834 - 838, 2009. http://dx.doi.org/10.1590/S0102-695X2009000600006

DALARMI, L. Estudo fitoquímico e avaliação das atividades biológicas da Dalbergia brasiliensis, Vogel. 2012. 109f. Dissertação (Mestrado em Ciências Farmacêuticas) Universidade Federal do Paraná, Curitiba, 2012.

DIAZ, P. Araribá (Centrolobium tomentosum Guillem. Ex Bentham - Fabaceae): revisão bibliográfica de essência nativa de grande potencial silvicultural. Revista do Instituto Florestal, São Paulo, v. 4, n. 2, p. 430 - 434, 1992.

ELISABETSKY, E.; SOUZA, G. C. Etnofarmacologia como ferramenta na busca de substâncias ativas. In: SIMÕES, C. M. O.; SCHENKEL, E. P.; GOSMANN, G.; MELlO, J. C. P.; MENTZ, L. A.; PETROVICK, P. R. (Orgs.). Farmacognosia: da planta ao medicamento. 5. ed. Porto Alegre: Editora da UFSC; Editora da UFRGS, 2003. p. 107-122.

ERBANO, M. Morfoanatomia de folha e caule das espécies Centrolobium tomentosum Guillemin ex Benth (Fabaceae), Genipa american L. e Randia armata (SW.) DC. (Rubiaceae). 2010. 82f. Dissertação (Mestrado em Ciências Farmacêuticas) - - Área de insumos, Medicamentos e Correlatos, Setor de Ciências da Saúde, Universidade Federal do Paraná, Curitiba, 2010.

FARMACOPÉIA DOS ESTADOS UNIDOS DO BRASIL. 2. ed. São Paulo: Indústria Gráfica Siqueira, 1959. 1265 p.

FOLIN, O.; CIOCALTEAU, V. On tyrosine and tryptophane determinations in proteins. Journal of biology and chemistry, v. 73, p. 424-427, 1927. 
FONSECA, P.; LIBRANDI, A. P. L. Avaliação das características físico-químicas e fitoquímicas de diferentes tinturas de barbatimão (Stryphnodendron barbatiman). Brazilian Journal of Pharmaceutical Sciences, São Paulo, v. 44, n. 2, p. 271-277, 2008 .

GONÇALVES, C. A.; LELIS, R. C. C.; ABREU, H. S. Caracterização Físico-Química da Madeira de Sabiá (Mimosa caesal-piniaefolia Benth.). Revista Caatinga, Mossoró, v. 23, n. 1, p. 54-62, jan./mar., 2010.

IGARASHI, M. A. Potencial econômico das Artemias poduzidas em regiões salineiras do Rio Grande do Norte. Pubvet, v. 2, n. 31, 2008.

KUSKOSKI, E. M.; ASUERO, A. G.; MORALES, M.T.; FETT R. Frutos tropicais silvestres e polpas de frutas congeladas: atividade antioxidante, polifenóis e antocianinas. Ciência Rural, Santa Maria, v. 36, n. 4, p. 1283-1287, jul./ago., 2006. http://dx.doi.org/10.1590/S0103-84782006000400037

LÓPEZ, C. A. A. Considerações gerais sobre plantas medicinais. Ambiente: Gestão e Desenvolvimento, v. 1, n. 1, p. 19-27, 2006.

MARTINEZ, D. T. Seleção genética de acacia mearnsii de wild. (acácia-negra) visando o aumento da qualidade e produtividade de madeira e tanino no rio grande do sul. 2006. 100f. Dissertação (Mestrado em Ciências Florestais) - Área de Ciências Florestais, Setor Ciências Agrárias, Universidade Federal do Paraná, Curitiba, 2006.

MAYORGA, P.; PÉREZ, K. R.; CRUZ, S. M.; CÁCERES, A. Comparison of bioassays using the anostracan crustaceans Artemia salina and Thamnocephalus platyurus for plant extract toxicity screening. Revista Brasileira de Farmacognosia, v. 20, n. 6, p. 897-903, 2010. http://dx.doi.org/10.1590/S0102-695X2010005000029

MEYER, B. N.; FERRIGNI, N. R.; PUTNAN, J. E.; JACOBSEN, L. B.; NICHOLS, D. E.; MCL. AUGHLIN, J. Journal of Medical Plant Research, v. 45, n. 1, p. 31-34, 1982. http://dx.doi.org/ 10.1055/s-2007-971236

MONTEIRO, J. M.; ALBUQUERQUE, U. P; ARAUJO, E. L.; CAVALCANTI DE AMORIM, E. L. Taninos: uma abordagem de química à ecologia. Química Nova, v. 28, p. 892-896, 2005. http://dx.doi.org/10.1590/S0100-40422005000500029

MOSSI, A. J.; MAZUTTI, M.; PAROUL, N.; CORAZZA, M. L.; DARIVA, C.; CANSIAN, R. L. et al. Chemical variation of tannins and triterpenes in Brazilian populations of Maytenus ilicifolia Mart. ex Reiss. Brazil Journal of Biology, v. 69, n. 2, p. 339-345, 2009. http://dx.doi.org/10.1590/S1519-69842009000200015

NGUTA, J. M.; MBARIA, J. M.; GAKUYA, D._W.; GATHUMBI, P._K.; KABASA, J._D.; KIAMA, S._G. Biological screening of Kenyan medicinal plants using Artemia Salina L. (Artemiidae). Pharmacologyonline 2, p. 458-478, 2011. Disponível em: http://www.unisa.it/uploads/4941/045.nguta.pdf. Acesso em: 2 fev. 2014.

PRASHANT, K._R.; DOLLY, J.; SINGH, K. R.; GUPTA, K. R.; WATAL, G. Glycemic properties of Trichosanthes dioica leaves. Pharmaceutical Biology, v. 46, n. 12, p. 894-899, 2008.

PAIVA S. R.; HERINGER A. P.; FIGUEREDO, M. R.; KAPLAN M. A. C. Taninos condensados de espécies de Plumbaginaceae. Floresta e Ambiente, v. 9, p. 153-157, 2002 . 
PINZON-TORRES, J. A.; SANTOS, V. R.; SCHIAVINATO, M. A.; MALDONADO S. Biochemical, histochemical and ultrastructural characterization of Centrolobium robustum (Fabaceae) seeds. Hoehnea, v. 36, n. 1. p. 149-160, 2009. http://dx.doi.org/10.1590/S2236-89062009000100009

REHMAN A. U.; MANNAN A.; INAYATULLAH, S.; AKHTAR, M. Z.; QAYYUM, M.; MIRZA, B. Biological evaluation of wild thyme (Tymus serpyllum). Pharmaceutical Biology, v. 47, suppl. 8, p. 628-633, 2009.

RODRIGUEZ, A. G.; TEIXEIRA, O. M.; SALlES, F. G.; VITAL, J. P.; PEIXOTO, D. S. Bioensaio com Artemia salina para detecção de toxinas em alimentos vegetais. Estudos, Goiânia, v. 36, n. 5/6, p. 795-808, 2009.

SIMÕES, C. M. O.; SCHENKEL, E. P.; GOSMANN, G.; MELLO, J. C. P de V. M.; AULER, L.; PETROVICK, P. R. Farmacognosia: da planta ao medicamento. 6 . ed. Porto Alegre: Ed. da UFRGS; Florianópolis: Ed. da UFSC, 2010.

SUBHAN, N.; ALAM, M. A.; AHMED, F.; SHAHID, I. J.; NAHAR, L.; SARKER, S. D. Bioactivity of Excoecaria agallocha. Revista Brasileira de Farmacognosia, v. 18, n. 4, p. 521-526, 2008. http://dx.doi.org/10.1590/S0102-695X2008000400004

TOSTES, A. S.; LELIS, R. C. C.; PEREIRA, K. R. M.; BRITO, E. O. Efeito da adição de tanino da casca de Eucalyptus pellita F. Muell ao adesivo Fenol-Formaldeído (FF) em chapas de partículas. Floresta e Ambiente. Seropédica, v. 12, n. 2, p. 50-56, 2005. 